\title{
The missing link: self-assessment and continuing professional development
}

\author{
C Redwood,* T Winning," G Townsend* \\ *Centre for Orofacial Research and Learning, School of Dentistry, The University of Adelaide, South Australia.
}

\begin{abstract}
The purpose of this paper is to review current understanding of the role of self-assessment in continuing education, particularly in the health professions, and to examine how this knowledge can assist in more effective continuing education. The ongoing debate over compulsory continuing professional development (CPD) has seen a variety of approaches proposed. CPD programmes are expected to foster self-assessing and self-directed practitioners, but the common structure is reported to be largely ineffectual in modifying behaviour. If dentistry is to maintain the rights and privileges of a selfregulating profession, then it must ensure that the development and judgement of ongoing competence is meaningful. Improving practitioners' knowledge of the how and why of effective self-assessment should improve participation in, and outcomes of, CPD. An oft-repeated observation is that the least competent are the most confident. If this is the case, then the idea that dentists should be able, or entitled, to choose the path of their continuing professional development must be open to question. We propose that development of the ability of practitioners to self-assess their ongoing requirements for CPD is essential if all stakeholders are to get the maximum return for effort.
\end{abstract}

Keywords: Continuing professional development, reflection, self-regulation, self-assessment.

(Accepted for publication 5 May 2009.)

\section{INTRODUCTION}

Self-assessment has long been identified as a vital ingredient in developing the self-directed and enquiring minds of health professionals, leading to lifelong learning and ensuring satisfactory ongoing professional self-regulation. ${ }^{1-6}$ Self-assessment or self-evaluation are often used as interchangeable descriptors of the ability of individuals to identify their inherent strengths and shortcomings. A self-regulating profession is accountable to its patients and the public in general for the development of the skills and knowledge they profess to hold, ${ }^{7,8}$ as well as the maintenance of ethical standards that place service before self, with specific obligations towards patients, colleagues and the profession. ${ }^{9,10}$ In many of the self-regulated professions, the concepts of self-assessment and self-directed learning are integral to undergraduate education, ongoing professional development and the maintenance of competence. This competence is usually measured by some form of periodic registration that is intended to be a public notice that practitioners are capable of providing care at a level commensurate with their qualifications. Thus, self-assessment has two synergistic components; those relating to ongoing knowledge and its development and application, as well as those relating to the behaviours and standards implied by membership of a profession.

Effective self-assessment is greater than the sum of the parts from which it is composed and it is a skill that is assumed more often than judged. While many studies have identified that the capacity to self-assess is essential for safe and effective practice and is a prerequisite for being an effective clinician, the consensus of opinion in the medical education literature is that individuals are not very accurate assessors of their own or even their peers' performance. ${ }^{2,11-15}$ Furthermore, they are unlikely to be able to correct, direct or identify their required learning. Therefore, there is a source of confusion for self-regulated health professions. Either the research indicating a lack of self-assessment skill is incorrect or a cornerstone of the continuing development and self-regulation of professions such as dentistry has little foundation. ${ }^{1}$

It is the intention of this paper to investigate the current literature in relation to self-assessment, predominantly in the clinical professions, and to draw some conclusions about how approaches to continuing professional development (CPD) may be influenced in 
the light of these findings. The paper concentrates on the research behind self-assessment and the methods used to try to measure the accuracy or efficacy of the process. In so doing, the component of self-assessment that is concerned with ethics is not discussed in any detail.

The concentration of research papers on how selfassessment outcomes compare with those of an expert or a gold standard performance has led to a jaundiced view of professionals' ability to self-assess. ${ }^{16}$ However, in attempting to quantify self-assessment, researchers have often overlooked the qualitative nature of the skill. A recent article ${ }^{17}$ exhorts us to look at the process in a more definitive way, drawing distinctions between selfassessment (an ability), with some of its components, namely reflection, self-monitoring and the search for external assessments of individual performance. This broader view of self-assessment is critical in dentistry, given that most practising dentists are the sole arbiters of the quality of their preferred treatment options. ${ }^{18}$

The litmus test of self-assessment ${ }^{16}$ is knowing or judging when knowledge or skill is lacking to an extent that the outcome of a clinical procedure could or would be compromised, and then acting appropriately. However, until we are able to understand the range of values that modify our self-assessment processes, and develop a sound basis on which to make comparisons about self-assessment abilities between professionals, there will always be latitude for the individual to accept the unacceptable.

A detailed review of the literature relating to selfassessment is beyond the scope of this paper, however multiple studies have been published over the past two decades on self-assessment, reflective practice and selfdirected learning in higher education, particularly in the health professions. ${ }^{1,2,19,20}$ Most of this work in relation to dentistry involves direct comparisons of estimated performance with achieved grades in clinical exercises or comparisons against a predefined or gold standard. ${ }^{5,13,21-23}$ This is useful research if our desire is to standardize clinical competence but, too often, the logical next step of influencing how participants understand and respond to self-assessment does not occur. Given that self-assessment of performance coincides so rarely with expert opinion, more effort should be directed at developing approaches by which systematic formative self-assessment activities could be incorporated into courses to improve the ability of participants to make reasoned and informed judgements about their own work. ${ }^{19}$

There will always be variation between individuals but, if it is possible to analyse and ensure that the key attributes of effective self-assessment are understood, it is anticipated that practising graduates would demonstrate enhanced self-regulation, an ongoing desire to learn and improved performance. To achieve this, an approach that encourages non-judgemental appraisal of effective self-assessing and self-reflective skills is needed. This approach should also promote a deeper understanding of what influences the individual in interpreting and applying these attributes for selfregulation. With reinforcement during $\mathrm{CPD}$, the practising professional would continue to be exposed to a greater understanding of the self-assessment process. It is pertinent to examine how research has investigated the process of self-assessment in order to gain an insight into how we may adapt the approach to CPD.

\section{Investigation of self-assessment, self-directed learning and reflection}

Self-assessment includes interpretation of feedback, which can vary from a purely summative list of correct answers in a test to comments or actions from a satisfied or dissatisfied patient. As Boud states "all acts of assessment involve more than is apparent, and we must judge them accordingly". ${ }^{24}$ A true measure of the effectiveness of self-assessment is difficult to formulate and both quantitative and qualitative studies have been undertaken to inform this area.

\section{Quantitative studies}

Quantitative studies include all those where an expert or gold standard is compared with a practitionergenerated result, and comparisons made between the scores. A recent review of methodologies used in the measurement of self-assessment found that three quantitative methods have been widely used, all of which are correlational designs. It is understood ${ }^{25}$ that peer assessment can be more accurate than self-assessment and this lends support to the argument that individuals can identify good and bad performances in others, but are unable or unlikely to apply these same criteria to their own performance.

Quantitative studies of assessment ability have been used most widely in the health professions. A recent review of the accuracy of self-assessment by physicians compared with observed measures of competence, chose studies with quantifiable and replicable measures that included practising physicians from the United Kingdom, Canada, the United States, Australia and New Zealand. ${ }^{2}$ A majority of these studies showed either little relationship between self- and expertassessment of performance, while a number found the least accurate assessment amongst those least skilled and most confident. The authors concluded that the preponderance of evidence suggested physicians have limited ability to self-assess accurately.

Most of the earlier quantitative research in dental education compared student and staff marks for operative procedures, and several studies attempted to 
predict clinical skill on previous tests of dexterity. ${ }^{26-28}$ Ericson and colleagues ${ }^{13}$ described the use of specific guidelines to enhance the self-assessment abilities of students. It appeared that the use of explicit guidelines improved the self-assessment process in clinical dentistry. ${ }^{13}$ The complex nature of many of the clinical skills in dentistry make the setting of an agreed set of criteria very difficult, so sufficient time is needed for practitioners as self-assessors to reach a degree of standardization and to avoid inconsistencies. ${ }^{23}$ It is essential that the continual review against standards of performance is understood by practitioners to be part of the responsibility for practice.

\section{Qualitative studies}

Perhaps self-assessment is more open to qualitative review and, indeed, there are many such papers from the health professions published over the last 10 years that are informative. In an editorial on self-assessment in medical practice, Colliver et al. ${ }^{16}$ state that "in practice self-assessment is inherently qualitative, concerned with specifics about subject matter and substance in a highly individualised, particularistic and contextual way".

Qualitative research related to self-assessment and self-regulation in dental education is in short supply. Boyd ${ }^{11}$ used qualitative research to identify what dental students reflect on during their early didactic and clinical experiences. It was observed that students often found the experience of connecting what had been learned in class with a real patient somewhat disorienting. Emotion seemed to be a fundamental attentive mechanism in the learning process, regulating what information was absorbed. This emphasizes the importance of exposing practitioners to appropriate role models early in their careers. Boyd concluded that reflection is an under-utilized strategy in dental education, and that it would lead to deeper learning associated with critical thinking. ${ }^{11}$

A recent paper $^{29}$ explored the understanding of undergraduate and postgraduate dental students about what constitutes good learning experience using reflection on action as described by Schon, ${ }^{30}$ with the intention of stimulating deep approaches to learning. The importance of repetition or discussion with peers and tutors in the learning process was noted, an observation of particular relevance if we are to see self-assessment as the cornerstone of future self-directed learning and the involvement of peers as mentors. This also highlights the necessity to provide adequate time and space in CPD programmes to enable these skill sets to be developed. There has been an emphasis in the past on post-task reflection as a means of self-assessment but we contend that there should be more focus on the "in task" performance and what it is that makes selfassessment such a personal endeavour.
The current state of the self-assessment debate is most strikingly illustrated by Eva and Regehr. ${ }^{1,17}$ After consideration of the published literature they concluded that focusing on the correctness of self-assessment misses the point that reflection in practice is the key element of self-reflection. "Self-assessment as a mechanism of ongoing monitoring must take precedence over self-assessment as a mechanism for identifying and redressing gaps."1

\section{Implications for practice - the "I" in the centre of the storm}

How then should we encourage and develop selfassessing, reflective and self-motivated practitioners and what do we need to provide to ensure selfassessment is successful?

Recently, the Commission on Change and Innovation in Dental Education ${ }^{15}$ provided a benchmark review that planners can use to assess the degree to which their curricula include learning opportunities associated with the development of problem solving, critical thinking, self-directed learning and other cognitive skills necessary for new dental graduates to become expert performers over time. They identified the development of problem solving and critical thinking skills as imperative and stated that "the dental education literature is fundamentally devoid of research on the cognitive components of clinical decision making".

Critical thinking relies on the ability to reflect on issues and to draw conclusions based on multiple factors, and there may be more than one best response. The following factors, originally described by the American educationalist and philosopher John Dewey, ${ }^{31}$ were listed by the Commission on Change and Innovation in Dental Education as underlying the process of reflective judgement: ${ }^{15}(1)$ identifying the issues and facts in a problem or dilemma; (2) identifying and exploring causal factors; (3) retrieving and assessing knowledge needed to appraise response options and guide actions; (4) comparing the strength and limitations of options; (5) skilfully implementing the option most likely to resolve the problem; (6) monitoring implementation and outcomes, and modifying the strategy/action as needed; and (7) candidly appraising the outcomes of actions, both positively and negatively.

The listed factors are just as relevant today as when they were formulated by Dewey. However, it is apparent from the literature that efforts involved in quantifying and/or qualifying the idea of self-assessment have led to a confused and occasionally conflicting situation. Concentration on the outcome has tended to lead us to ignore the logical key - the "self" in "selfassessment", the individual in self-regulation.

Although we may be able to supply a supportive environment and ensure that all the principles of 
defining criteria and providing feedback are observed, until the practitioner is enlightened about some of the characteristics of the "self", such as their personality and their perception of themselves and others, the selfassessment process will continue to be less effective than we would hope.

\section{What's the point - how does self-assessment impact continuing education?}

The effectiveness of mandatory CPD has been the subject of many reports, with little evidence provided that there are extensive benefits in improving the quality of care or the professional behaviour of health practitioners. $^{32,33}$ It is not the intention of this paper to comment specifically on the content or form of delivery of any programme of continuing development, as there are many expert bodies around the world intimately involved in research in this area. ${ }^{34-37}$ However, the ongoing requirement for effective self-assessment appears extremely relevant.

Practitioners choice of CPD programmes is often driven by them having a special interest in a subject, the speaker or the desire to gain an expanded skill, rather than because they have identified deficiencies in their knowledge or skill base. A recent review on selfassessment noted that people are better able to recognize proficiencies and shortcomings in their skill base than in their knowledge base, ${ }^{38}$ and if mandatory CPD is in place, the convenience of time and place may be a deciding factor in which courses are attended. A conclusion from a recent systematic review ${ }^{39}$ on ongoing education found a troubling result in relation to older "experienced" practitioners: they were found to need quality improvement interventions in order to be considered to provide adequate care. Indeed, current continuing education techniques were found to be largely ineffective in this regard. ${ }^{39}$ While there is no evidence to suggest that dental patients are being put at risk in daily practice, we are all aware of treatment plans or courses of treatment that were unsuitable or poorly performed. While there is no doubt that experience can be a marvellous teacher, every dentist must know that amongst their most basic duties of care is to do no harm.

For the concept of the self-directed, self-assessed and self-regulated professional to remain credible, continuing professional development must include some audit of self-assessment skills. ${ }^{38}$ Thus, within the mandatory component of CPD, research shows the need to expose ourselves to the uncomfortable notion of peer review or peer assessment in order to develop our ability to better understand our strengths and to identify deficiencies in knowledge or skills that need to be addressed. ${ }^{40}$ The separation of CPD from the essential examination of competence for registration would ensure practitioners saw continuing education as non-judgemental, encouraging participation in areas they may not otherwise explore.

To do this does not require extensive psychological profiling, nor does it infer that effective self-assessment skills cannot be learned. It means that until individuals can make reasoned judgements of their own strengths and weaknesses, and of how differing character traits interact, then some of the usefulness of reflection will be lost. The stability and integrity of the self-assessment process is in continual flux, influenced primarily by the physical and emotional environment and the state of being of the individual. It is this variation in an individual's behaviour and also their different responses to any given situation that make self-assessment so subjective. ${ }^{41}$ In order to reduce this subjectivity and improve the effectiveness of self-assessment it would seem to be beneficial to inform practitioners about how character traits are defined and described, so that they are better able to see how they may be perceived by others, and how they can more effectively participate in a group or modify their own or the group's behaviour. The group may be colleagues, associates or even a single patient.

\section{CONCLUSIONS}

We contend that the development of self-assessment skills needs to become an integral component in the ongoing education of dental practitioners. Self-assessment should not be seen as merely a mechanism for identifying deficiencies in knowledge or skill but rather as a comprehensive system of ongoing monitoring. CPD planners need to provide enough time and space within their programmes to enable participants to develop selfassessment skills, with the appropriate support and mentoring provided to ensure that the "self" in selfassessment is emphasized. As a profession, we must strive to improve our understanding of the self-assessment process, as it is, in our view, the missing link needed to ensure that the CPD programmes of the future lead to the development of truly reflective, selfregulating practitioners.

\section{REFERENCES}

1. Eva KW, Regehr G. Self-assessment in the health professions: a reformulation and research agenda. Acad Med 2005;80:S46-S54.

2. Davis DA, Mazmanian PE, Fordis M, Van Harrison R, Thorpe KE, Perrier L. Accuracy of physician self-assessment compared with observed measures of competence: a systematic review. JAMA 2006;296:1094-1102.

3. Gruppen LD, White C, Fitzgerald JT, Grum CM, Woolliscroft JO. Medical students' self-assessments and their allocations of learning time. Acad Med 2000;75:374-379.

4. Langendyk V. Not knowing that they do not know: self-assessment accuracy of third-year medical students. Med Educ 2006; 40:173-179. 
5. Lindemann RA, Jedrychowski J. Self-assessed clinical competence: a comparison between students in an advanced dental education elective and in the general clinic. Eur J Dent Educ 2002;6:16-21.

6. Ward M, Gruppen L, Regehr G. Measuring self-assessment: current state of the art. Adv Health Sci Educ Theory Pract 2002;7:63-80.

7. Welie JVM. Is dentistry a profession? Part 1. Professionalism defined. J Can Dent Assoc 2004;70:529-532.

8. Duffy FD, Holmboe ES. Self-assessment in lifelong learning and improving performance in practice: physician know thyself. JAMA 2006;296:1137-1139.

9. Welie JVM. Is dentistry a profession? Part 2. The hallmarks of professionalism. J Can Dent Assoc 2004;70:599-602.

10. Australian Dental Association Inc. Principles of ethical dental practice. ADA Policy Statement 5.4. 7-8 April 2005.

11. Boyd LD. Reflections on clinical practice by first-year dental students: a qualitative study. J Dent Educ 2002;66:710-720.

12. Friedman Ben David M, Davis MH, Harden RM, Howie PW, Ker J, Pippard MJ. AMEE Medical Education Guide No. 24: Portfolios as a method of student assessment. Med Teach 2001;23:535-551.

13. Ericson D, Christersson C, Manogue M, Rohlin M. Clinical guidelines and self-assessment in dental education. Eur J Dent Educ 1997;1:123-128.

14. Eva KW, Cunnington JP, Reiter HI, Keane DR, Norman GR. How can I know what I don't know? Poor self assessment in a well-defined domain. Adv Health Sci Educ Theory Pract 2004; 9:211-224

15. Hendricson WD, Andrieu SC, Chadwick DG, et al. Educational strategies associated with development of problem-solving, critical thinking, and self-directed learning. J Dent Educ 2006;70: 925-936.

16. Colliver JA, Verhulst SJ, Barrows HS. Self-assessment in medical practice: a further concern about the conventional research paradigm. Teach Learn Med 2005;17:200-201.

17. Eva KW, Regehr G. "I'll never play professional football" and other fallacies of self-assessment. J Contin Educ Health Prof 2008;28:14-19.

18. Ellis JS, Hobson RS, Waterhouse PJ, et al. Tutor perceptions of the use of a reflective portfolio within a pastoral tutor system to facilitate undergraduate personal development planning. Eur J Dent Educ 2006;10:217-225.

19. Boud D, Falchikov N. Quantitative studies of student selfassessment in higher education: a critical analysis of findings. Higher Education 1989;18:529-549.

20. Colthart I, Bagnall G, Evans A, et al. The effectiveness of selfassessment on the identification of learner needs, learner activity, and impact on clinical practice: BEME Guide No. 10. Med Teach 2008;30:124-145.

21. Mattheos N, Nattestad A, Falk-Nilsson E, Attstrom R. The interactive examination: assessing students' self-assessment ability. Med Educ 2004;38:378-389.

22. Leisnert L, Mattheos N. The interactive examination in a comprehensive oral care clinic: a three-year follow up of students' self-assessment ability. Med Teach 2006;28:544-548.

23. Scott BJJ, Evans DJP, Drummond JR, Mossey PA, Stirrups DR. An investigation into the use of a structured clinical operative test for the assessment of a clinical skill. Eur J Dent Educ 2001;5:3137.

24. Boud D. Sustainable assessment: rethinking assessment for the learning society. Studies in Continuing Education 2000;22:151167.

25. Dochy F, Segers M, Sluijsmans D. The use of self-, peer and co-assessment in higher education: a review. Studies in Higher Education 1999;24:331-350.
26. Forehand LS, Vann WF Jr, Shugars DA. Student self-evaluation in preclinical restorative dentistry. J Dent Educ 1982;46:221226.

27. Vann W, May K, Shugars D. Aquisition of psychomotor skills in dentistry: an experimental teaching method. J Dent Educ 1981;45: 567-575.

28. Oudshoorn WC. The utility of Canadian DAT perceptual ability and carving dexterity scores as predictors of psychomotor performance in first-year operative dentistry. J Dent Educ 2003;67: 1201-1208.

29. Ashley FA, Gibson B, Daly B, Baker SL, Newton JT. Undergraduate and postgraduate dental students' 'reflection on learning': a qualitative study. Eur J Dent Educ 2006;10:1019.

30. Schon D. The Reflective Practitioner. New York: Basic Books, 1983:105-267.

31. Dewey J. Democracy and education: an introduction to the philosophy of education. Revised edition. New York: Free Press, 1997.

32. Hopcraft M, Marks G, Manton D. Participation in continuing professional development by Victorian dental practitioners in 2004. Aust Dent J 2008;53:133-139.

33. O'Brien MA, Freemantle N, Oxman AD, Wolf FM, Davis DA, Herrin J. Continuing education meetings and workshops: effects on professional practice and health care outcomes. Cochrane Database of Systematic Reviews 2001; Issue 1.

34. Dornan T. Self-assessment in CPD: lessons from the UK undergraduate and postgraduate education domains. J Contin Educ Health Prof 2008;28:32-37.

35. Schleyer T, Eaton K, Mock D, Barac'h V. Comparison of dental licensure, specialization and continuing education in five countries. Eur J Dent Educ 2002;6:153-161.

36. Prescott LE, McKinlay P, Rennie JS. The development of an assessment system for dental vocational training and general professional training: a Scottish approach. Br Dent J 2001;190: 41-44.

37. Davis DA, O'Brien MA, Freemantle N, Wolf FM, Mazmanian PE, Taylor-Vaisey A. Impact of formal continuing medical education: do conferences, workshops, rounds and other traditional continuing education activities change physician behaviour or health care outcomes? J Am Med Assoc 1999;282: 867-874.

38. Colthart I, Bagnall G, Evans A, et al. The effectiveness of selfassessment on the identification of learner needs, learner activity, and impact on clinical practice: BEME Guide No. 10. Med Teach 2008;30:124-145.

39. Choudhry NK, Fletcher RH, Soumerai SB. Systematic review: the relationship between clinical experience and quality of health care. Ann Intern Med 2005;142:260-273.

40. Friedman A, Phillips M. Continuing professional development: developing a vision. Journal of Education and Work: Routledge, 2004:361-376.

41. Dunning D, Heath C, Suls JM. Flawed self-assessment. Implications for health, education, and the workplace. Psychol Sci Public Interest 2004;5:69-106.

Address for correspondence:

Dr Christopher Redwood

Centre for Orofacial Research and Learning School of Dentistry

The University of Adelaide

Adelaide SA 5005

Email:redwoodc@bigpond.net.au 